\title{
GESTÃO DA CRIAÇÃO DE CONHECIMENTO NA INDÚSTRIA CRIATIVA DE SOFTWARE ${ }^{1}$ \\ MANAGEMENT OF THE CREATION OF KNOWLEDGE IN THE CREATIVE INDUSTRY OF SOFTWARE
}

\author{
Marcos Antonio Gaspar ${ }^{2}$ \\ Denis Donaire ${ }^{3}$ \\ Maria Conceição Melo Silva ${ }^{4}$ \\ Carolina de Fátima Marques Maia ${ }^{5}$ \\ Eduardo Pinto Vilas Boas ${ }^{6}$ \\ Silvio Aparecido dos $\operatorname{Santos}^{7}$
}

\begin{abstract}
RESUMO: A capacidade de inovação é essencial à sobrevivência de empresas criativas de software. Assim, a criação e disseminação do conhecimento encontram cada vez mais espaço no planejamento e na estratégia de gestão dessas organizações. Este estudo, de natureza exploratória, efetuou entrevistas semi-estruturadas com profissionais gestores e técnicos da indústria criativa de software, tendo por objetivo analisar as técnicas e métodos presentes no processo de geração e disseminação do conhecimento, bem como as ferramentas de tecnologia da informação voltadas a essa finalidade. Os principais resultados mostram que há uma preocupação constante nessas organizações com a geração do conhecimento. As técnicas e métodos mais largamente empregados na criação e disseminação de conhecimento foram: brainstorming, reuniões presenciais, reuniões virtuais, treinamentos oficiais presenciais, treinamentos informais, cursos em universidades, compartilhamento de experiências, discussões e aplicativo de gestão de projetos de desenvolvimento de software. Já em relação às ferramentas utilizadas, somam-se: internet, intranet, aplicativos específicos, redes internas, repositórios de dados, diretórios específicos no banco de dados e sistemas de telefonia baseados na internet.
\end{abstract}

PALAVRAS-CHAVE: Gestão do conhecimento. Indústria criativa. Indústria de software.

ABSTRACT: The innovation capacity is essential to the survival of creative companies of software. Thus, the creation and dissemination of knowledge reach more and more importance in the planning and the management strategy of these companies. This exploratory study performed semi-structuralized interviews with managers and technicians of the creative industry of software. The objective was to analyze the techniques and methods applied in the process of knowledge generation and dissemination, as well as the Information Technology tools applied for this purpose. The main results show that these companies have a constant concern about the generation of the knowledge. The most applied techniques and methods used in the knowledge creation and dissemination were: brainstorming, physical presence meetings, virtual meetings, physical presence official training, informal training, courses in university, sharing of experiences, quarrels and of project management software. About the applied tools: Internet, Intranet, specific software, internal nets, data repositories, directories in the data base and phone systems based in the Internet.

KEY WORDS: Knowledge management. Creative industry. Software industry.

\footnotetext{
${ }^{1}$ Artigo Recebido em 20.01.2009. Revisado por pares em 05.06.2009. Recomendado em 12.03.2010 por Leomar dos Santos Editor. Publicado em 26.04.2010.

Organização Responsável pelo periódico: Universidade Regional de Blumenau - FURB - www.furb.br/rn
}

\footnotetext{
${ }^{2}$ Universidade Municipal de São Caetano do Sul - USCS - marcos.gaspar@uscs.edu.br

${ }^{3}$ Universidade Municipal de São Caetano do Sul - USCS - $\underline{\text { denisdon@uscs.edu.br }}$

${ }^{4}$ Universidade Federal de Sergipe - UFSE - ceica@infonet.com.br

${ }^{5}$ Universidade Federal de Pernambuco - UPE - carolmmaia@gmail.com

${ }^{6}$ Universidade São Paulo - FEA-USP - duvilasboas@gmail.com

${ }^{7}$ Universidade São Paulo - FEA-USP - sadsanto@usp.br
} 


\section{INTRODUÇÃO}

A idéia presente no senso comum de que 'o mundo está mudando' já se faz um fato consumado na percepção das pessoas. O que talvez nem todas elas tenham percebido é que as mudanças estão cada vez mais aceleradas, criando descontinuidades que afetam a todos. Essa visão sobre a envergadura desses processos de mudança é muito bem explorada por Castells (1999), ao discorrer sobre a nova realidade introduzida pelo que o autor chamou de Sociedade da Informação. Ou seja, as bases estruturais da sociedade industrial, nas quais e através das quais nossos ascendentes forjaram nossa formação social, têm sido profundamente alteradas.

Dessa forma, no atual cenário dinâmico que se impõe ao mundo corporativo, o conhecimento desempenha um papel fundamental na diferenciação de uma organização perante os seus pares em seu ambiente de atuação. Apesar da geração do conhecimento ser vital, no sentido de propiciar criatividade e inovação às organizações, faz-se necessário ainda que haja eficácia no processo de criação desse conhecimento, de tal sorte que proporcione mudanças que efetivamente agreguem valor às organizações. Para a viabilização desse complexo mecanismo, adiciona-se às ferramentas disponíveis da Tecnologia da Informação e Comunicação (TIC), um processo bem estruturado e gerido que proporcione às organizações a gestão da criação do conhecimento. Ou seja, a evolução e até a própria sobrevivência de uma organização estão profundamente calcados na criação do conhecimento e, para tanto, um processo bem estruturado, aliado às ferramentas da TIC podem disponibilizar a correta disseminação desse conhecimento gerado entre os colaboradores da organização. Dessa forma, conforme Nonaka e Takeuchi (1997), a organização deve estimular a auto-recriação de seu sistema de conhecimentos, encontrando assim novas formas de pensar e desenvolver as suas atividades, produtos e serviços.

Especificamente na indústria criativa de software, a criação de conhecimento assume papel de insumo imprescindível ao sucesso da organização. A indústria de software é intrinsecamente calcada no binômio criatividade e inovação, tendo nesses atributos a sua natural evolução. A inventividade presente nas organizações dessa indústria faz com que haja constantemente um forte fluxo criativo, maciça e necessariamente aplicado em seus produtos e serviços. Nesse sentido, mais do que capital financeiro, propriedades materiais ou ainda a marca e imagem das organizações da indústria criativa de software, a criatividade e inovação perfazem-se como o fiel da balança que as eleva à posição de vencedoras nessa indústria.

Portanto, a análise do processo de criação e disseminação do conhecimento, bem como das ferramentas da TIC presentes em organizações desenvolvedoras de software, é mandatária para uma melhor compreensão do sucesso das organizações vencedoras nessa indústria criativa. Assim, este estudo analisou três empresas de desenvolvimento de software atuantes na indústria brasileira de software, locadas nas regiões de São Paulo (SP), Campinas (SP) e Recife (PE). Nestas organizações buscou-se diagnosticar as técnicas e métodos empregados no processo de criação e disseminação de conhecimento, além das ferramentas de TIC utilizadas em suas atividades internas voltadas a suportar essa finalidade.

\section{REFERENCIAL TEÓRICO}

\subsection{O Conhecimento}

O conhecimento, na visão clássica da cultura grega, era considerado algo de certa forma inabalável e inquestionável. Já Nonaka e Takeuchi (1997) propõem que o conhecimento seja encarado como um processo pragmático e essencialmente humano, sempre 


\section{GESTÃO DA CRIAÇÃO DE CONHECIMENTO NA INDÚSTRIA CRIATIVA DE SOFTWARE}

em contínuo desenvolvimento. Davenport e Prusak (1998) sugerem que o conhecimento seja composto pela informação avaliada na mente humana, incluindo-se aí, respectivamente: reflexão, síntese e contextualização. Para Fleck (1997) deve-se ainda associar mais uma importante característica ao conhecimento: o significado que este dá às coisas e fatos. Ou seja, o conhecimento é o que capacita as pessoas a agirem e lidarem de forma inteligente com todas as fontes de informação disponíveis através da aplicação prática das informações recebidas.

Assim, depreende-se que o conhecimento seja inerente ao desenvolvimento do homem, sob quaisquer condições. Tendo-se ainda como premissa de que o homem é um ser essencialmente sociável em sua busca por vida coletiva, pode-se compreender que as organizações, que são feitas por seres humanos, compõem-se em elementos perfeitos para a farta geração e disseminação de conhecimento. Ao refletirmos sobre termos atuais tais como 'sociedade da informação' ou 'sociedade do conhecimento', temos a exata medida da importância desse ativo para as organizações contemporâneas.

Davenport e Prusak (1999) discorrem que o conhecimento possa gerar retornos crescentes e novas perspectivas para as organizações, principalmente na medida em que os ativos do conhecimento aumentam com o seu uso, uma vez que idéias geram novas idéias e o conhecimento compartilhado enriquece todos aqueles que dele participam. Nonaka (2001) enfatiza que a compreensão das idéias, intuições e conhecimentos tácitos existentes na organização seja imprescindível para o sucesso das instituições modernas. Segundo Cavalcanti, Gomes e Pereira (2001) o conhecimento, e não tão somente o acesso às informações, é que tem propiciado o verdadeiro distanciamento das organizações, regiões e países líderes em relação aos demais.

\subsection{A Gestão da Criação e Disseminação do Conhecimento}

No atual cenário competitivo que se apresenta às empresas, a criação e disseminação de conhecimento nas organizações devem ser encaradas como atividades nevrálgicas ao suporte e viabilização da estratégia empresarial. Para tanto, a criação e disseminação desse conhecimento gerado deve produzir resultados econômicos reais. Assim, Ferreira e Neves (2005) apontam dois fatores que devem ser observados pelas organizações: a capacidade de operar com agilidade em conseqüência do uso crescente de operações virtuais oriundas de configurações organizacionais em rede, e o aumento expressivo de investimentos em aprendizagem organizacional, com foco no binômio formação pessoal e implantação de sistemas informatizados. Ou seja, as organizações devem se esforçar para introduzir duas vertentes: um processo estruturado para criação do conhecimento entre seus colaboradores e a disponibilização de ferramentas de Tecnologia da Informação e Comunicação que suportem a criação e disseminação desse conhecimento gerado na organização.

Segundo Nonaka e Takeuchi (1997) o conhecimento humano pode ser categorizado em dois tipos: tácito e explícito. Conhecimento tácito é aquele que está na mente das pessoas, possuindo forte ligação com a experiência de cada indivíduo, difícil de ser compartilhado e dependente da história de vida de cada um, de seus valores e modelos mentais; ou seja, seria o conhecimento subjetivo. Já o conhecimento explícito é codificado e pode ser encontrado em documentos e projetos, sendo materializado no próprio produto, ou seja, o conhecimento objetivo.

De forma complementar, Choo (2006) propõe que haveria três dimensões do conhecimento: conhecimento tácito, conhecimento explícito e conhecimento cultural. Sendo os dois primeiros semelhantes à idéia de Nonaka e Takeuchi (1997), acrescentando o conhecimento cultural que consiste nas estruturas cognitivas e afetivas que são habitualmente 
utilizadas pelos membros da organização com o intuito de perceber, explicar, avaliar e construir a realidade. Um conhecimento não codificável, mas facilmente difundido pelos elos que conectam o grupo.

Nonaka (1990) entende que o processo de criação e disseminação do conhecimento seja antes de tudo um processo de conversão social, no qual o conhecimento tácito e o conhecimento explícito se expandem dentro da organização em termos qualitativos e quantitativos. A viabilização dessa conversão é apresentada por Nonaka e Takeuchi (1997) através de um modelo que representa quatro modos de conversão de conhecimento: socialização, externalização, combinação e internalização, conforme exposto na Figura 1 a seguir.

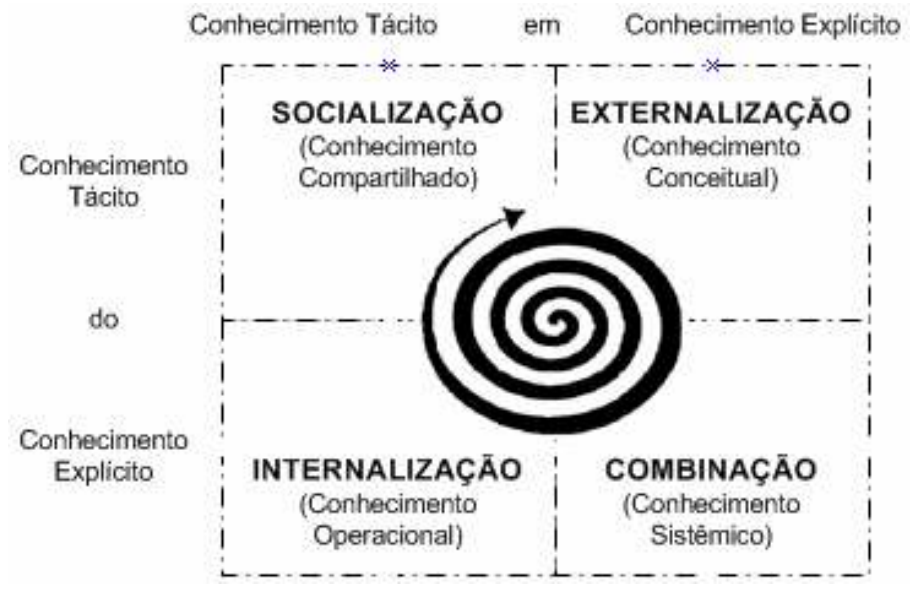

Figura 1 - Quatro modos de conversão de conhecimento Fonte: Nonaka e Takeuchi (1997, p. 81).

A socialização consiste no compartilhamento das experiências entre os indivíduos, que aprenderiam através da observação e interação uns com os outros, sem necessariamente utilizar a linguagem. Esse modo de criação de conhecimento seria um importante ativo na aquisição do conhecimento tácito. Já externalização é um processo de articulação do conhecimento tácito em conceitos explícitos, notadamente através do compartilhamento de metáforas, analogias, modelos ou histórias, ocorrendo geralmente através do diálogo e da reflexão coletiva. É muito importante para a criação do conhecimento, uma vez que gera conceitos novos e explícitos a partir do conhecimento tácito. A combinação é um processo de organização de conceitos em um sistema de conhecimento. Ou seja, é o modo pelo qual partes até então incompatíveis de conhecimento explícito já existentes se combinam, criando assim um novo conhecimento explícito. Finalmente, na internalização verifica-se o processo de incorporação do conhecimento explícito em conhecimento tácito. Está intimamente relacionada ao 'aprender fazendo', principalmente através de modelos mentais ou expertise técnica compartilhados. Nela há a aprendizagem e socialização mediante a repetição de uma tarefa, a fim de que os conhecimentos explícitos transformem-se em conhecimento tácito (NONAKA e TAKEUCHI, 1997).

\subsection{A Indústria Criativa}

O termo indústria criativa surgiu nos anos 1990, primeiramente em estudos provenientes da Inglaterra e Austrália. Atualmente contempla os setores e organizações nas 


\section{GESTÃO DA CRIAÇÃO DE CONHECIMENTO NA INDÚSTRIA CRIATIVA DE SOFTWARE}

quais a criatividade seja uma dimensão essencial, tais como publicidade, cinema, teatro, artesanato, arquitetura, design, música, indústria editorial, rádio, TV e desenvolvimento de software.

Assim sendo, a partir do momento em que as nações industrializadas moveram-se da produção de bens e serviços para a produção de idéias e conhecimento, a indústria criativa tornou-se objeto de uma crescente quantidade de pesquisas, aumentando-se dessa forma o conteúdo teórico existente sobre o tema. São exemplos pioneiros desses estudos os trabalhos promovidos por Landry e Bianchini (1995), Csikszentmihalyi (1996), O'Connor e Wynne (1996) e Robinson (2001).

Uma definição muito difundida para o termo 'indústria criativa' foi exposta pelo Departamento de Cultura, Mídia e Esportes do governo britânico em 1998, e resgatada por Jones et al (2004), qual seja: indústrias criativas são organizações que têm origem na criatividade, habilidade e talento individuais, tendo ainda potencial para geração de prosperidade e criação de empregos através da exploração de propriedade intelectual. Entretanto, Tepper (2002) argumenta que é muito difícil encontrar um consenso sobre os limites conceituais da indústria criativa. Porém, uma característica em comum que todas as organizações devem ter é a idéia do esforço criativo oriundo do conhecimento gerado pela própria organização, como premissa básica de sua razão de existir. Corroborando tal idéia, Cook (1998) acredita que o conhecimento e a criatividade sejam importantes fontes de competitividade para as organizações pertencentes à indústria criativa.

Robinson e Stern (1997) sugerem que as organizações criativas devam adotar um processo de alinhamento, no qual a inclinação e as ações de todos os funcionários estejam direcionadas aos objetivos da organização: geração de conhecimento e inovação. Para tanto, Jones et al (2004) atestam que muitas das organizações representantes da indústria criativa aproveitam o poder das atuais ferramentas de Tecnologia da Informação e Comunicação para contribuir para o desenvolvimento global de outras organizações, sendo tal atitude uma parte central da inovação que é uma de suas marcas registradas.

Assim, as indústrias criativas caracterizam-se por distribuírem bens e serviços baseados em textos, símbolos e imagens, formando um agrupamento distinto de atividades fundamentadas no conhecimento e na propriedade intelectual, além de combinar talento criativo, técnicas e tecnologias avançadas, tal como efetuado na indústria criativa de software.

\subsection{A Indústria Brasileira de Software}

A indústria de computadores nasceu de forma integrada, seguindo-se, progressivamente, a desmembramentos em diferentes componentes, dentre os quais o software que deixou de ser um acessório do hardware quando a IBM passou a oferecê-los separadamente. Dessa forma, a IBM passou a comercializar seus computadores apenas com o sistema operacional, incluindo assim os softwares aplicativos no rol dos componentes que poderiam ser ofertados por outras empresas. Tal condição é considerada como ato de fundação do mercado de software e, por conseqüência, da indústria de software (CAMPOS, NICOLAU e CARIO 2000; OCDE, 2005).

Existem diversos tipos de softwares, que vão desde sistemas comerciais aos acadêmicos, de sistemas operacionais até os jogos de computador, que são sistemas interativos que representam um subconjunto da realidade, de acordo com Crawford (2002). Devido à diversidade de tipos de software existente, dados da $\operatorname{OCDE}(2005$, p. 17) revelam que "as empresas de todos os setores da economia investem cada vez mais em software, e a participação nominal do software na formação de capital fixo bruto do setor empresarial 
cresce de maneira constante desde 1990". Isto porque as aplicações dos softwares atingem uma gama cada vez mais vasta de atividades, fazendo com que as ações de pesquisa e desenvolvimento sejam cada vez mais intensificadas para atender a demanda das diversas atividades.

Nesta direção, dentre as indústrias criativas, a de software (programas e soluções lógicas), possui um diferencial devido aos aspectos de usabilidade, utilidade e velocidade com os quais os aplicativos são desenvolvidos, conforme Tapscott e Caston (1995). Além disso, a indústria de software valoriza mais o capital humano do que os bens de produção, assim como o trabalho colaborativo.

Roselino (2006) indica que o Brasil tem uma preocupação com a indústria de software, destacando-se assim duas metas norteadoras: que o Brasil seja referência na exportação de software e serviços correlatos; e que ocorra uma ampliação das empresas nacionais no mercado interno. Nesse sentido, o mercado doméstico de software é significativo, com pólos de desenvolvimento em todas as regiões do país, notadamente com maior concentração de empresas no Sudeste e no Sul do país, sendo a maioria formada por empresas de pequeno porte, segundo considerações de Kubota (2006). Externamente, aproveitando as capacidades locais em muitos segmentos e nichos específicos, busca-se a internacionalização de sua indústria de software. Com isso, Barros (2007) enfatiza que o Brasil entende que as políticas para as indústrias criativas são nacionais na origem, mas globais em sua perspectiva e que assim como ocorre na Índia e o Chile, o Brasil já estabeleceu seu nicho global na indústria criativa de produção de software.

A evolução da indústria de software no Brasil tem se intensificado de forma bastante acelerada. Em 2004, essa indústria obteve um faturamento de US\$ 1,74 bilhões, em 2005 de US\$ 2,72 bilhões e em 2006 alcançou a cifra de US\$ 3,26 bilhões, o que equivale a 1,3\% do mercado mundial e 43\% do mercado latino americano (BRASIL, 2006; ABES, 2007). A expansão do mercado conquistado nos últimos anos faz com que empresas estrangeiras se interessem em realizar grandes investimentos no país, sendo cada vez mais importantes ações governamentais que promovam as empresas nacionais, estimulando-as não só a competir pelo mercado interno como, também, a buscar novos mercados no exterior (FREIRE e BRISOLA, 2004).

A incerteza e dinamicidade são características do ambiente da indústria de software, que intrinsecamente é calcada no binômio criatividade e inovação, para atender a demanda de informação dos aplicativos a serem criados. Desta forma, no caso específico da indústria criativa de software, a criação e disseminação de conhecimento assumem o papel de insumos imprescindíveis ao sucesso desse tipo de organização.

\section{METODOLOGIA}

Este é um estudo exploratório de natureza qualitativa, feito a partir de entrevistas realizadas junto a empresas brasileiras desenvolvedoras de software. As três empresas selecionadas foram escolhidas a partir de critérios de conveniência e acessibilidade para a coleta de dados, sendo representativas à medida que relatam as experiências dessas organizações, bastante significativas na área de desenvolvimento de software interativo voltado ao lazer. As organizações pesquisadas estão localizadas nas regiões metropolitanas de São Paulo (SP), Campinas (SP) e Recife (PE).

A razão da escolha de software voltado ao lazer deve-se à importância crescente desse segmento de mercado na indústria do software como um todo. Assim selecionou-se três empresas que têm destaque no cenário brasileiro. A empresa A está situada no Porto Digital, 


\section{GESTÃO DA CRIAÇÃO DE CONHECIMENTO NA INDÚSTRIA CRIATIVA DE SOFTWARE}

um arranjo produtivo local de organizações voltadas à Tecnologia da Informação e Comunicação da cidade do Recife (PE), e tem como produto principal o desenvolvimento de jogos para aparelhos celulares. A empresa foi vencedora do Prêmio Nacional de Empreendedorismo Inovador 2006, realizado pela Associação Nacional de Entidades Promotoras de Empreendimentos - ANPROTEC e recebeu o segundo lugar do Prêmio FINEP de Inovação Tecnológica 2006 da região Nordeste, na categoria pequena empresa.

A empresa B tem sede em São Paulo (SP) e desenvolve software de jogos interativos em computador voltados à prática pedagógica de ensino fundamental. Seus principais produtos são comercializados em todo o país, tendo ampla utilização em instituições de ensino fundamental para inserção da criança ao mundo da informática, além de dezenas de milhares de usuários finais residenciais.

A empresa $\mathrm{C}$ está localizada em Campinas (SP), tendo como principal produto o desenvolvimento de conteúdo interativo para páginas de internet. A empresa conta com importantes parcerias com outras organizações do país, bem como vínculos com empresas estrangeiras, visando o desenvolvimento conjunto de alguns aplicativos específicos.

Quadro 1 - Principais características das empresas analisadas.

\begin{tabular}{|c|c|c|c|}
\hline Características & $\begin{array}{l}\text { Empresa A } \\
\text { (Recife) }\end{array}$ & $\begin{array}{l}\text { Empresa B } \\
\text { (São Paulo) }\end{array}$ & $\begin{array}{l}\text { Empresa C } \\
\text { (Campinas) }\end{array}$ \\
\hline Segmento de atuação da empresa & Jogos de Celular & Jogos de computador & $\begin{array}{c}\text { Conteúdo interativo } \\
\text { para web }\end{array}$ \\
\hline Porte / Abrangência & Pequeno / Nacional & Médio / Nacional & Pequeno / Nacional \\
\hline $\begin{array}{l}\text { Quantidade de colaboradores na } \\
\text { empresa envolvidos com a } \\
\text { criação/disseminação do } \\
\text { conhecimento }\end{array}$ & $\begin{array}{lr}\text { Gestores: } & 2 \\
\text { Analistas: } & 9 \\
\text { Total: } & 11\end{array}$ & $\begin{array}{lr}\text { Gestores: } & 8 \\
\text { Analistas: } & 31 \\
\text { Total: } & 39\end{array}$ & $\begin{array}{lr}\text { Gestores: } & 3 \\
\text { Analistas: } & 13 \\
\text { Total: } & 16\end{array}$ \\
\hline $\begin{array}{l}\text { Quantidade de colaboradores } \\
\text { pesquisados }\end{array}$ & $\begin{array}{ll}\text { Gestores: } & 1 \\
\text { Analistas: } & - \\
\text { Total: } & 1 \\
\end{array}$ & $\begin{array}{ll}\text { Gestores: } & 2 \\
\text { Analistas: } & 2 \\
\text { Total: } & 4 \\
\end{array}$ & $\begin{array}{l}\text { Gestores: } \\
\text { Analistas: } \\
\text { Total: }\end{array}$ \\
\hline
\end{tabular}

Fonte: autores da pesquisa.

Para atingir os objetivos do estudo (delineamento das principais características da criação e disseminação do conhecimento gerado pela organização, bem como as técnicas e métodos, além das ferramentas de TIC utilizadas), a coleta de dados foi efetuada em duas frentes mutuamente complementares:

a) Entrevistas direcionadas feitas junto aos gestores com poder de decisão (diretores, gerentes, coordenadores, supervisores e/ou líderes de equipes). Durante as entrevistas buscou-se o levantamento e entendimento das principais características desenvolvidas na criação e disseminação do conhecimento produzido na organização;

b) Entrevistas direcionadas feitas junto aos funcionários técnicos (analistas de sistemas, analistas de ambiente/plataforma, analistas de banco de dados, consultores, programadores, testadores e documentadores). De forma complementar a fase anterior, esta etapa visou confrontar e validar os conteúdos verificados no levantamento feito junto aos gestores pesquisados. Dessa forma, buscou-se compreender a visão desses profissionais quanto às principais características desenvolvidas na geração e disseminação do conhecimento na organização. 
Ou seja, as duas vertentes pesquisadas complementam-se no atendimento aos objetivos da pesquisa. Foi elaborado um roteiro de entrevista visando direcionar os questionamentos feitos a cada um dos perfis dos sujeitos da pesquisa (gestores e analistas). Tal ação, além de propiciar maior padronização em relação ao conteúdo buscado em cada uma das três organizações pesquisadas, também colaborou para o melhor andamento das entrevistas.

\section{ANÁLISE DOS RESULTADOS}

Os resultados da pesquisa são expostos a seguir. Optou-se por estruturar a demonstração dos resultados a partir do delineamento feito no roteiro de pesquisa aplicado a cada um dos sujeitos pesquisados.

\subsection{A gestão da criação e disseminação de conhecimento na empresa}

Os sujeitos entrevistados, em maior ou menor grau, atestaram ter consciência de que a organização produz conhecimento ao desenvolver suas ações cotidianas. Além de captar afirmações diretas sobre a geração de conhecimento internamente, também foi possível depreender durante as entrevistas vários exemplos de geração interna de conhecimento por parte dos colaboradores envolvidos. A ênfase nas atividades de P\&D (Pesquisa e Desenvolvimento) foi exposta demonstrando que há uma busca constante por geração de conhecimento dentro da organização. Os sujeitos gestores entrevistados demonstraram uma compreensão mais explícita quanto à geração interna do conhecimento desenvolvido nas organizações pesquisadas, expondo que isso inclusive ocorria, em parte, como objetivo almejado em suas atividades de gestão. Já os sujeitos analistas pesquisados disseram ter consciência de que suas atividades geravam conhecimento à empresa, porém entendiam que o conhecimento gerado por eles tem características mais técnicas e específicas aos produtos em si.

Embora notoriamente com diferentes características e históricos em relação à geração do conhecimento interno, as empresas pesquisadas pareceram convergir em relação à questão da disseminação do conhecimento. Em todas as organizações foi diagnosticada a existência de técnicas, métodos e ferramentas para a disseminação do conhecimento gerado pela empresa, mesmo observando-se uma variação de intensidade da frequência de uso de cada técnica, método ou ferramenta.

\subsection{A contribuição do conhecimento gerado para o sucesso competitivo da empresa}

Os sujeitos pesquisados argüiram que, uma vez sendo a área de desenvolvimento de software a essência do próprio negócio da organização (core business) em sua indústria de atuação, notoriamente a geração de conhecimento era responsável direta pelo sucesso da empresa. O conhecimento é visto como um bem que a empresa deve preservar e expandir. Assim sendo, o valor da empresa está nas pessoas e no conhecimento que elas geram. Em algumas falas pôde-se verificar espontaneamente que, tanto gestores quanto analistas, têm uma percepção bastante pragmática da responsabilidade de seus papéis no sucesso competitivo da organização. Questões como criatividade, inovação, antecipação aos concorrentes, disponibilização de diferenciais no produto e busca pelo estado da arte; foram 


\section{GESTÃO DA CRIAÇÃO DE CONHECIMENTO NA INDÚSTRIA CRIATIVA DE SOFTWARE}

levantadas para justificar o conhecimento gerado internamente como algo intrínseco ao resultado do produto final da empresa: o software. Também foram lembradas as premiações e reconhecimentos recebidos pela empresa junto as associações, órgãos públicos ou interinstitucionais, clientes e parceiros de negócio.

\subsection{A empresa como elemento facilitador da criação e disseminação de conhecimento}

De uma forma geral, os sujeitos vistos entendem que as suas organizações facilitam e até estimulam a criação do conhecimento gerado internamente. Na empresa $\mathrm{A}$, o gestor expôs que a organização busca internalizar a importância da geração do conhecimento em seus colaboradores, notadamente através de motivação de seus recursos humanos. Como medida prática, a empresa permite inclusive o acesso a cursos externos (pós-graduação ou outros) durante o horário de trabalho.

$\mathrm{Na}$ empresa B, a criação e expansão de conhecimento são instigadas em todos os participantes. Um dos entrevistados até recorreu à missão da empresa, que notoriamente inspira em seus colaboradores a busca por inovações advindas de pesquisa e desenvolvimento constantes. De forma complementar, também foram expostos exemplos de políticas de recursos humanos voltadas ao estímulo da criação de conhecimento, através de diferentes mecanismos desenvolvidos pela empresa.

Já os entrevistados da empresa $C$ observam que a criação de conhecimento é, em grande parte, propiciada por ações individuais ou de pequenos grupos. Ou seja, eles não observam que a organização tenha, de forma consistente, uma visão já sedimentada que sustente a geração do conhecimento junto aos seus pares, embora até seja o conhecimento um tema presente em diversas interações ocorridas por indivíduos/áreas dentro da organização.

\subsection{As formas de conversão de conhecimento praticadas na empresa}

Quanto ao modelo de conversão do conhecimento proposto por Nonaka e Takeuchi (1997), verifica-se que as organizações analisadas não exploram apropriadamente os quatro modos de conversão de conhecimento propostos pelos autores. Ou seja, há um desbalanceamento em relação à intensidade com a qual cada uma das vertentes é praticada. Tal situação pode representar um problema e, ao mesmo tempo, um desafio à empresa: há algumas deficiências no processo de geração e disseminação de conhecimento ao mesmo tempo em que constata-se a possibilidade de melhorias a serem implementadas para propiciar avanços nesse processo. O Quadro 2 expõe a visão das empresas em relação às suas percepções quanto à intensidade de uso dos modos de conversão de conhecimento propostos pelo modelo de Nonaka e Takeuchi (1997):

Quadro 2 - Percepção da intensidade de uso de cada modo de conversão do conhecimento do Modelo de Nonaka e Takeuchi

\begin{tabular}{l|c|c|c}
\cline { 2 - 3 } \multicolumn{1}{c|}{ Fase } & Empresa A (Recife) & $\begin{array}{c}\text { Empresa B (São } \\
\text { Paulo) }\end{array}$ & $\begin{array}{c}\text { Empresa C } \\
\text { (Campinas) }\end{array}$ \\
\hline Socialização & Pouco executado & Executado & $\begin{array}{c}\text { Executado } \\
\text { Externalização }\end{array}$ \\
Combinação & Executado & Executado \\
Muito executado \\
Internalização & Muito executado & Muito executado \\
\hline
\end{tabular}

Fonte: autores da pesquisa. 
Os modos de conversão de conhecimento mais praticados pelas empresas analisadas foram a Combinação e a Internalização. Nesses dois modos é possível verificar o tratamento do conhecimento explícito, de identificação e processamento muito mais fácil e tangível pelas organizações.

\subsection{Principais técnicas e métodos empregados na gestão da criação e disseminação de} conhecimento

Para a formulação do roteiro de entrevistas aplicado aos sujeitos da pesquisa, foi elaborada uma lista de técnicas e métodos que destinavam-se à tal finalidade, colhidos a partir do referencial teórico consultado. Não obstante, além de indagar sobre a frequência de uso de cada uma das técnicas e métodos constantes no roteiro de entrevistas, também foram recebidas novas contribuições a partir das citações dos entrevistados. Assim sendo, as principais técnicas e métodos empregados na geração e disseminação de conhecimento nas empresas, bem com as intensidades percebidas, estão expostas no Quadro 3:

Quadro 3 - Técnicas e métodos empregados pelas empresas analisadas.

\begin{tabular}{|c|c|c|c|}
\hline \multirow[t]{2}{*}{ Técnicas e métodos } & \multicolumn{3}{|c|}{ Freqüência de uso } \\
\hline & Alta & Média & Baixa \\
\hline Brainstorming (reuniões para geração de idéias para resolução de problemas) & & A, B & $\mathrm{C}$ \\
\hline Reuniões presenciais & $\mathrm{A}, \mathrm{B}, \mathrm{C}$ & & \\
\hline Reuniões virtuais & A, B & $\mathrm{C}$ & \\
\hline Palestras presenciais & & $\mathrm{B}$, & $\mathrm{A}, \mathrm{C}$ \\
\hline Palestras virtuais & & & $\mathrm{B}$ \\
\hline Treinamentos oficiais presenciais & $\mathrm{B}$ & $\mathrm{A}, \mathrm{C}$ & \\
\hline Treinamentos oficiais virtuais $\mathrm{c} /$ instrutores à distância & & & B \\
\hline Auto Treinamento virtual oficial & & & B \\
\hline Treinamentos informais & A, B & $\mathrm{C}$ & \\
\hline Participação em grupos internos de estudo e pesquisa & A & B & $\mathrm{C}$ \\
\hline Participação em grupos externos de estudo e pesquisa & & & $\mathrm{A}, \mathrm{C}$ \\
\hline Membro de associações/instituições externas & & $\mathrm{B}, \mathrm{C}$ & A \\
\hline Participação em outros grupos externos & & & $\mathrm{A}, \mathrm{B}$ \\
\hline Interação com a matriz, filiais, representantes, parceiros de negócio & B & & $\mathrm{C}$ \\
\hline Auto-didatismo dos funcionários & A & B & $\mathrm{C}$ \\
\hline $\begin{array}{l}\text { Cursos externos em universidade (cursos de curta duração, graduação, pós- } \\
\text { graduação, etc.) }\end{array}$ & A & $\mathrm{B}, \mathrm{C}$ & \\
\hline Cursos externos em outras instituições & & B & $\mathrm{A}, \mathrm{C}$ \\
\hline Compartilhamento de experiências & $\mathrm{A}, \mathrm{B}, \mathrm{C}$ & & \\
\hline Observação, imitação e prática (mentoring) & & B & $\mathrm{A}, \mathrm{C}$ \\
\hline Interações entre indivíduos na empresa & $\mathrm{A}, \mathrm{B}, \mathrm{C}$ & & \\
\hline Diálogos e reflexões coletivas & B & $\mathrm{A}, \mathrm{C}$ & \\
\hline Uso de metáforas, analogias e modelos & & $\mathrm{B}$ & $\mathrm{A}, \mathrm{C}$ \\
\hline Troca de documentos e relatórios oficiais & $\mathrm{A}, \mathrm{B}, \mathrm{C}$ & & \\
\hline Diálogos (conference calls, chats) & $\mathrm{A}, \mathrm{B}, \mathrm{C}$ & & \\
\hline $\begin{array}{l}\text { Produção de experiências orais, verbalização, elaboração de documentos } \\
\text { baseados em experiências e vivências }\end{array}$ & A, B & $\mathrm{C}$ & \\
\hline FAQ (Frequently Asked Questions - Questões mais frequentes) & A & B & \\
\hline Fórum de discussões & $\mathrm{A}, \mathrm{B}$ & & $\mathrm{C}$ \\
\hline Parâmetros norteadores da qualidade no desenvolvimento de software & $\mathrm{A}, \mathrm{B}, \mathrm{C}$ & & \\
\hline Aplicativo de gestão de projetos de desenvolvimento de software & $\mathrm{A}, \mathrm{B}$ & $\mathrm{C}$ & \\
\hline
\end{tabular}

Legenda: A (empresa A); B (empresa B); C (empresa C).

Fonte: autores da pesquisa. 


\section{GESTÃO DA CRIAÇÃO DE CONHECIMENTO NA INDÚSTRIA CRIATIVA DE SOFTWARE}

As principais técnicas e métodos utilizados na criação e disseminação de conhecimento nas empresas pesquisadas foram: brainstorming, reuniões presenciais, reuniões virtuais, treinamentos oficiais presenciais, treinamentos informais, cursos em universidades, compartilhamento de experiências, interações entre indivíduos na empresa, troca de documentos e relatórios oficiais, diálogos entre os colaboradores, produção de experiências orais/documentais baseadas em vivências, fórum de discussões, parâmetros de qualidade e aplicativo de gestão de projetos de desenvolvimento de software. Outras técnicas e métodos também foram encontrados no levantamento, porém com frequência de utilização menor do que as demais citadas anteriormente.

A partir desse cenário, pode-se depreender que as organizações analisadas têm um ferramental diversificado à disposição para a criação e disseminação do conhecimento gerado internamente.

\subsection{Principais ferramentas de TIC empregadas na gestão da criação e disseminação de conhecimento}

As empresas analisadas têm uma natural facilidade para a utilização de ferramentas de Tecnologia da Informação e Comunicação, uma vez que atuam na indústria de software. Não obstante, a partir da pesquisa efetuada foi possível delinear quais as ferramentas de TIC são mais utilizadas pelas organizações em seu processo de criação e disseminação de conhecimento. O Quadro 4 exibe as ferramentas de TIC e suas respectivas freqüências de uso.

Quadro 4 - Ferramentas de Tecnologia da Informação e Comunicação empregadas pelas empresas analisadas.

\begin{tabular}{|c|c|c|c|}
\hline \multirow[t]{2}{*}{ Ferramentas da Tecnologia da Informação e Comunicação } & \multicolumn{3}{|c|}{ Freqüência de uso } \\
\hline & Alta & Média & Baixa \\
\hline Internet & $\mathrm{A}, \mathrm{B}, \mathrm{C}$ & & \\
\hline Intranet & $\mathrm{A}, \mathrm{B}, \mathrm{C}$ & & \\
\hline Extranet & & B & \\
\hline Software específico (gestão de projetos, gestão de manutenção) & $\mathrm{A}, \mathrm{B}$ & $\mathrm{C}$ & \\
\hline Redes internas & $\mathrm{A}, \mathrm{B}, \mathrm{C}$ & & \\
\hline Repositório de dados interno & $\mathrm{A}, \mathrm{B}, \mathrm{C}$ & & \\
\hline Diretórios específicos internos & $\mathrm{A}, \mathrm{B}, \mathrm{C}$ & & \\
\hline Software de Business Inteligence & & & B \\
\hline Sistemas de telefonia baseados na internet & $\mathrm{A}, \mathrm{B}, \mathrm{C}$ & & \\
\hline Sistemas de telefonia tradicionais & $\mathrm{B}$ & $\mathrm{A}, \mathrm{C}$ & \\
\hline Sistemas/repositórios específicos para transmissão/armazenamento de dados & & $\mathrm{B}$ & \\
\hline
\end{tabular}

Legenda: A (empresa A); B (empresa B); C (empresa C).

Fonte: autores da pesquisa.

As ferramentas de TIC mais utilizadas na criação e disseminação do conhecimento interno gerado pelas organizações vistas são: Internet, Intranet, software específico, redes internas, repositórios de dados, diretórios específicos no banco de dados e sistemas de telefonia baseados na Internet. Tais ferramentas são largamente empregadas por essas empresas, viabilizando de forma direta o processo de criação e disseminação do conhecimento na organização.

\section{CONSIDERAÇÕES FINAIS}

O conhecimento existente em uma organização pode desempenhar um papel fundamental na diferenciação de uma empresa perante os seus pares em seu ambiente de atuação. Para tanto, é imprescindível que haja eficácia na criação e disseminação dos 
conhecimentos gerados internamente pelas organizações. Questões como criatividade, inovação e novos valores agregados ao produto, só podem se viabilizar a partir de uma correta geração e disseminação do conhecimento na empresa. Para tanto, a boa utilização de técnicas e métodos destinados a esse fim, bem como o emprego das ferramentas da TIC atualmente existentes, podem efetivamente colaborar para a viabilização desse processo com sucesso.

Tais ponderações mostram-se ainda mais contundentes se analisarmos a indústria criativa de software, que já é uma realidade representativa no cenário econômico do país. As organizações inseridas nessa indústria são intrinsecamente voltadas à geração e disseminação de conhecimentos, até por conta de sua própria razão de existência. Ou seja, a evolução e até a própria sobrevivência de uma organização de desenvolvimento de software estão profundamente calcadas na criação e disseminação do conhecimento gerado internamente.

Em relação ao grau de consciência que os entrevistados têm sobre a criação do conhecimento interno, pôde-se verificar que os sujeitos entrevistados, em maior ou menor grau, atestaram ter consciência de que a organização produz conhecimento ao desenvolver suas ações cotidianas. Os gestores pesquisados têm uma percepção mais explícita desse processo, enquanto que os analistas observam que sua contribuição na geração de conhecimento tem caráter mais técnico e circunscrito aos produtos. Já sobre a contribuição do conhecimento gerado para o sucesso competitivo da empresa, os entrevistados têm clara percepção de que suas ações de geração de conhecimento são decisivas para o êxito da organização. Tal afirmação provém do entendimento de que suas atividades estejam fundamentalmente ligadas à essência do negócio da organização (core business). Ou seja, eles têm noção de que desempenham a atividade-fim da empresa e o quanto tal responsabilidade pode influenciar no sucesso da organização.

Os sujeitos entrevistados entendem que, de forma genérica, as empresas facilitam e até estimulam a criação do conhecimento. No caso da empresa A, busca-se até a internalização de tal consciência junto aos colaboradores, através de motivação de seus recursos humanos. $\mathrm{Na}$ empresa B a criação e expansão do conhecimento são instigadas em todos os participantes, inclusive de forma institucionalizada através da missão e de políticas praticadas pela organização. Já na empresa $\mathrm{C}$, pôde-se identificar uma maior proação de indivíduos e grupos internos no sentido de viabilizar a criação de conhecimento. Ou seja, a organização estimula, mas ainda não possui de forma consistente processos que auxiliem na geração de conhecimento. Relativamente à disseminação do conhecimento nas empresas analisadas, houve uma maior convergência. Isso porque foi possível verificar a existência de técnicas, métodos e ferramentas para a disseminação do conhecimento gerado pelas empresas.

As empresas pesquisadas apresentam um desbalanceamento em relação às formas de conversão de conhecimento propostas por Nonaka e Takeuchi (1997). Assim, os modos mais praticados encontrados nas organizações pesquisadas foram a Combinação e a Internalização. Talvez tal resultado deva-se ao fato de que nesses dois modos seja factível verificar mais abertamente o tratamento do conhecimento explícito, de identificação e processamento muito mais fáceis e tangíveis pelas organizações.

As principais técnicas e métodos utilizados na criação e disseminação de conhecimento nas empresas pesquisadas foram: brainstorming, reuniões presenciais, reuniões virtuais, treinamentos oficiais presenciais, treinamentos informais, cursos em universidades, compartilhamento de experiências, interações entre indivíduos na empresa, troca de documentos e relatórios oficiais, diálogos entre os colaboradores, produção de experiências orais/documentais baseadas em vivências, fórum de discussões, parâmetros de qualidade e aplicativo de gestão de projetos de desenvolvimento de software. Já em relação às ferramentas de TIC empregadas, as organizações analisadas demonstraram contar com: Internet, Intranet, software específico, redes internas, repositórios de dados, diretórios específicos no banco de 


\section{GESTÃO DA CRIAÇÃO DE CONHECIMENTO NA INDÚSTRIA CRIATIVA DE SOFTWARE}

dados e sistemas de telefonia baseados na Internet. Tais ferramentas são largamente empregadas pelas empresas pesquisadas, viabilizando assim a criação e disseminação do conhecimento na organização.

A principal contribuição desse estudo junto às organizações representativas da indústria criativa de software de interatividade e lazer diz respeito às conclusões aqui descritas, que podem constituir-se em importantes indicativos para outras empresas que pretendam melhor compreender e gerir seus processos de criação e disseminação de conhecimento. Uma limitação desse estudo deve-se ao fato de que a pesquisa feita não ter caráter estatístico. Portanto, embora importantes, os indicativos aqui expostos não são passíveis de generalizações extensivas a toda a indústria criativa de software interativo e de lazer. No entanto, estudos futuros poderiam dar andamento às questões aqui levantadas no sentido de verificar qualitativamente a utilização das técnicas e métodos levantados na criação e disseminação do conhecimento gerado internamente pela empresa. De forma extensiva, outros trabalhos poderiam explorar a utilização das ferramentas de TIC identificadas neste estudo, bem como analisar a gestão do conhecimento gerado pelas empresas desse segmento, ou ainda de outros segmentos da indústria de software, que não os ligados à interatividade e lazer.

\section{REFERENCIAS}

ABES - Associação Brasileira das Empresas de Software. Mercado brasileiro de software: Panorama e 2007. 2007. Dendências Disponível em: $<$ http://www.abes.org.br/templ3.aspx?id=306\&sub=247>. Acesso em: 29 nov. 2007.

BARROS, Maria do S. M. de. A indústria criativa em Pernambuco: criatividade e tecnologia digital na produção do cinema local. In: CONGRESSO BRASILEIRO DE CIÊNCIAS DA COMUNICAÇÃO, XXX, Santos, 2007. Anais... Santos, 29 ago. a 02 set. 2007.

BRASIL. Ministério da Ciência e Tecnologia - MCT. Mercado de software cresce 6,1\% em $2004 . \quad$ Disponível em: $<$ http://www.mct.gov.br/Temas/info/Imprensa/Noticias_4/Software_4.htm>. Acesso em: 03 de out. 2007.

CAMPOS, Renato R.; NICOLAU, José A.; CARIO, Sílvio F. A indústria de software de Joinville: um estudo de caso de arranjo inovativo local. Instituto de Economia da Universidade Federal do Rio de Janeiro - IE/UFRJ. Rio de Janeiro, out. 2000.

CAVALCANTI, M.; GOMES, E.; PEREIRA, A. Gestão de empresas na sociedade do conhecimento. Rio de Janeiro, Campus, 2001.

CASTELLS, Manuel. A sociedade em rede. A era da informação: economia, sociedade e cultura. São Paulo: Paz e Terra, 1999.

CHOO, W. C. A organização do conhecimento: como as organizações usam a informação para criar significado, construir conhecimento e tomar decisões. São Paulo: Editora Senac, 2006.

COOK, P. The creativity advantage is your organisation the leader of the pack?. Industrial and Commercial Training, Guilsborough, v. 30, n. 5, p. 179-84, 1998. 
CRAWFORD, Chris. The art of computer games. Whashington: Washington State University. 2002.

CSIKSZENTMIHALYI, M. Creativity: flow and psychology of discovery and invention. New York: Harper Collins, 1996.

DAVENPORT, T.; PRUSAK, L. Conhecimento empresarial: como as organizações gerenciam seu capital intelectual. Rio de Janeiro: Campus, 1999.

Ecologia da informação: por que só a tecnologia não basta para o sucesso na era da informação. São Paulo: Futura, 1998.

FERREIRA, M. A.; NEVES, J. T. Informação, conhecimento e empreendedorismo: alimentando a dinâmica de inovação tecnológica na província do Quebec, Canadá. In: ENCONTRO DA ASSOCIAÇÃO NACIONAL DE PÓS-GRADUAÇÃO E PESQUISA EM ADMINSTRAÇÃO, XXIX, 2005, Brasília, Anais... Rio de Janeiro: ANPAD, 2005.

FLECK, J. Contingent knowledge and technological development. Technology Analisys \& Strategic Management. Londres: Carfax, v. 9, n. 4, p. 383-397, dec. 1997.

FREIRE, E.; BRISOLLA, S. de N. A contribuição do caráter "transversal" do software para a política de inovação. Revista Brasileira de Inovação, v. 4, n. 1, jan./jun. 2005.

JONES, P.; COMFORT, Daphne.; EASTWOOD, I.; HILLIER, David. Creative industries: Economic contributions, management challenges and support initiatives. Management Research News. Patrington, v. 27, n. 11/12, 2004.

KUBOTA, Luis Claudio. Desafios para a indústria de software. Textos para discussão. Brasília: IPEA, jan. $2006 . \quad$ Disponível em: <http://www.ipea.gov.br/pub/td/2006/td_1150.pdf>. Acesso em: 03 out. 2007.

LANDRY, C.; BIANCHINI, F. The creative city. London: Demos, 1995.

NONAKA, Ikujiro. A theory or organizational knowledge creation. New York: Prentice Hall, 1990.

NONAKA, Ikujiro. A empresa criadora do conhecimento. In: Gestão do conhecimento Harvard Business Review. Rio de Janeiro: Campus, 2001.

NONAKA, Ikujiro; TAKEUCHI, Hirotaka. Criação de conhecimento na empresa. 9 ed. Rio de Janeiro: Campus, 1997.

OCDE - Organização de Cooperação e Desenvolvimento Econômicos. Perspectivas da tecnologia da informação: as tecnologias da comunicação e da informação e a economia da informação. São Paulo: Senac, 2005.

O'CONNOR, J.; WYNNE, D. From the margins to the centre: Cultural production and consumption in the post-industrial city. Aldershot: Arena, 1996.

ROBINSON, K. Out of our minds: Learning to be creative. London: Capstone, 2001. 
GESTÃO DA CRIAÇÃO DE CONHECIMENTO NA INDÚSTRIA CRIATIVA DE SOFTWARE

ROBINSON, A. G.; STERN, S. Corporate creativity. Saxton: Berrett Kochler Publishers, 1997.

ROSELINO, J. E. Análise da indústria brasileira de software com base em uma taxonomia das empresas: subsídios para a política industrial. Revista Brasileira de Inovação, v. 5, n. 1, jan./jun. 2006.

TAPSCOTT, D.; CASTON A. Mudança de paradigma. São Paulo: Makron Books, 1995.

TEPPER, S. J. Creative assets and the changing economy. Journal of Arts Management, Law and Society, Montreal, v. 5, n. 2, Winter 2002. 